\title{
Microfinance and its Role in Women Empowerment ${ }^{*}$
}

\section{Dr. Hala Helmy EL Hadidi}

\author{
Associate Professor \\ Programme Director, Business Department \\ Faculty of Business Administration, Economics and Political Science \\ The British University in Egypt
}

\begin{abstract}
Microcredit has become one of the most important tools used to fight poverty and to enhance families' wellbeing. This research aims at testing the following hypothesis: microcredit is positively linked to women's socio-economic wellbeing in Cairo; it uses primary source data and has a public policy orientation. The results confirmed what was previously reported in the literature, namely the high correlation between microcredit and children's education, income and assets and disproved studies that found microcredit to improve health and harmony in the family.
\end{abstract}

Key words: Microcredit; Women; Socio-economic wellbeing; Egypt

\section{Introduction}

The current Egyptian socio-economic context imposes lots of constraints on women's employment and can sometimes degrade their socio-economic status, obliging them to join the labor market under very harsh conditions. On the other hand, different studies showed that the implementation of structural adjustment policies have had negative impacts on women and their wellbeing (Ritu, 2015; Elson, 2014; Doumato and Posusney, 2013). In this context, microcredit is being proposed and used internationally as a tool to fight poverty. Women are specifically targeted by some of these programs because some studies suggested that giving women credit has a multiplier effect since women invest largely in their households.

This article aims first, at confirming or refuting a positive link between microcredit and the socio-economic wellbeing of women in Cairo and second, to explore the context in which microcredit programs function in Egypt and the way their performance can be improved. Thus, given that very few if not all studies were previously carried out to measure the impact of microcredit programs on beneficiaries in Egypt; the aim is to shed some light on the following questions:

- What can be expected from the offer of microcredit on the welfare of recipients?

- Under what conditions would such an offer be more beneficial?

The research hypothesis formulated is that microcredit is positively linked to the socioeconomic wellbeing of women in Cairo in terms of: income, possession of assets, children's schooling, health and harmony in the family. The methodology used was mainly quantitative, using correlation and regression analyses of cross-sectional data. Interview questions were included in order to reflect the details concerning the satisfaction of women vis a vis the

\footnotetext{
* This article was submitted in May 2016, and accepted for publishing in August 2016.
} 
microcredit program. Interviews were also made with the microcredit program directors and microcredit specialists in Egypt in order to deepen, give a qualitative dimension to the analysis and help in the interpretation of the results, thus answering the second question pertaining to the functioning of microcredit programs and leading to policy recommendations. In most studies, recommendations are presented without trying to further investigate the actual usefulness and efficiency of the offer of microcredit. Therefore, the relevance of this research is first of a scientific nature as it tries to confirm or refute the utility of a tool that has been largely discussed in studies as efficient for poverty reduction and empowerment. Secondly, it is relevant for the intervention and decision making by presenting policy recommendations and implications.

\section{Literature Review}

Microcredit or more generally micro financing is a term that indicates "the offer of financial services to customers with low income levels" (Nader, 2008). Thus, micro financing targets people with very low income and having no access to the formal lending system.

Different theories showed the importance of microcredit as a tool to boost economic growth, to counteract the effects of economic instability and to empower women. In fact, when women, who would otherwise stay at home and dedicate their time to reproductive tasks, integrate the labor market; new opportunities emerge to them. Microcredit is specifically important for women because they often lack the necessary collaterals and preconditions to obtain a credit from a formal lending institution. On the other hand, microcredit programs are increasingly targeting women due to the following reasons: first, a costefficiency rationale since women's repayment rates are much higher than men, second, an equity reason because women have less access to productive employment in the developing countries and third, because women invest largely in their children and households, engendering a multiplier effect that improves the effectiveness of the credit funds. The offer of microcredit is supported by different developmental schools and groups of experts, each according to their ideology. First, the defenders of 'development serving people' argue that microcredit puts people in the heart of the process of development and policies elaboration. Second, the women's rights defenders believe that microcredit empowers women since it promotes development while focusing on eliminating gender differences. Third, the poverty reduction approach encourages the offer of microcredit because it empowers the poor, make them economically independent and less vulnerable when facing economic crises. Finally, the offer of microcredit is supported by the economic growth experts because it promotes the development of the least advantaged and developed regions, promoting growth over the long term. Furthermore, the 'added worker effect' theory shows that during economic recessions and in the context of an increase in unemployment, when the main bread earner of a family is unemployed or a deterioration in the household's income occurs, another member of the household seeks employment in order to compensate for the decline in the total welfare. This theory gains more importance in the context of the absence of adequate social security schemes (Cerrutti, 2013). The theory of the 'The possession of economic resources index' explains that adapting to economic changes and crises requires a minimal possession of resources that would be redirected according to the new economic trends. But women in developing countries are rarely owners of significant economic resources, which make them very vulnerable when facing economic crises. In fact, studies show that for the poor, the lack of financial resources is a big constraint to undertaking economic activities. In this context, 
the offer of microcredit is a tool used in developing countries to combat poverty on one hand and to correct market failures on another hand. A study argues that in the case of very poor households where savings are very costly because of low total income and where consumption is minimal allowing basic survival needs, microcredit plays a very important role in enhancing the household's wellbeing (Sinha, 2010). The concept of empowerment is also central in the rationale of the offer of microcredit to women. It reflects the capacity of women to undertake new economic activities.

From the perspective of 'poverty combat', this term is defined as the process of giving more power to the poor without any considerations of age, sex, religion or ethnicity in order to benefit from the fruits of development and to actively take part of the decision-making process in order to challenge the structures that exclude them from that process.

As for the strategies used to offer microcredit, according to El Solh C., socio-economist at the United Nations (1999), two microcredit strategies exist to answer the needs of two different targeted groups. The "protectionist" or "survival" strategy aims the very poor recipients to whom survival is the main concern. In this case, low amounts of credit are offered, allowing them to answer very urgent and basic needs of consumption through very modest economic activities. The "promotional" approach is when the amount of credit is higher and targets less poor recipients permitting substantial investment in income generating activities. This differentiation is very important in analyzing the outcomes of a microcredit program, as we will see in the discussion of our results.

There are two different approaches in measuring the impact of the microcredit offering: The "Institutionist" approach highlights the practical/institutional aspects of the offer, namely the financial sustainability and outreach of microcredit programs. The "Welfarist" approach on the other hand focuses on improvements realized by microcredit on the recipients' wellbeing (Chaves and Gonzalez-Vega, 2010; Buckley, 2014). The first approach is used to financially justify the use of the resources dedicated to the microcredit programs while the second one is more appealing to donors and researchers. The "welfarist" approach is the one that will conceptually guide our own research work. Furthermore, two different approaches exist to make the link between microcredit and women's empowerment: the minimalist approach suggest that microcredit empowers women by positively increasing their economic independence and making them more capable of responding to their households' needs (Hashemi et al., 2013). A wider approach considers that besides the economic empowerment, microcredit has also a positive impact on women's self-esteem, political participation, etc. (El Solh, 1999). Although the minimalist approach supports the formulation of our hypotheses, the wider one helps in the discussion of the results and explains the answers given by women.

Finally, it should be specified that in the case of Egypt, the offer of microcredit falls under a context where two ideologies clash: The first, the "gender" ideology, have always managed the relations between men and women. It confirms the place of the man in the society as the bread winner, and provider of the financial safety of the family, while a woman is confined to reproductive roles at the house, as wife and mother. The balance of power inside the household is always in favor of the man who holds the decision-making power. The second one, the "labor" ideology is recent and entails that the employment of women is a need for the survival of their household. The new ideology is reinforced in the case of very 
disadvantaged households and those where families depend on the woman as the principal bread winner, a situation according to statistics, affecting 25\% of Egypt's households (Kabeer, 2016). The pressure put by economic conditions has led to the preponderance of the "labor" ideology over the traditional "gender" ideology. Even more, today some people tend to say that women work does not contradict the traditional ideology as it is a prolongation of their role as mothers providing the basic needs of their families.

\section{Choice of Variables of the Study}

Our research represents a summative evaluation, more specifically; a socio-economic impact analysis. Khander (1998) shows that in spite of the importance of the evaluation of microcredit programs in term of their financial sustainability and outreach, such criteria do not necessarily reflect the real impact on the society and the beneficiaries. Consequently, our research as well as the choice of the variables falls under the previously mentioned welfarist approach in measuring the impact of the microcredit. The variables were chosen to represent the socio-economic wellbeing of women. These variables are: the income, the possession of assets, the schooling of the girls, the schooling of the boys, the perception of health and the perception of the harmony in the family. These variables were chosen for the following reasons:

\section{Income}

All the studies undertaken in the various countries showed that obtaining a microcredit would increase the income of the recipients while enabling them to widen their activity and to increase the quantity of the goods they sell (Nelson et al., 1996; Johnson and Rogaly, 2010; Creevey, 2013). This effect is particularly important in Egypt in the context of the feminization of poverty. As mentioned earlier, more than $25 \%$ of the households depend today on the woman as the principal source of income.

\section{Assets}

Guided by the literature, the possession of assets was retained as a second variable because this variable reflects the sustainability of the effect of microcredit (Nelson et al., 1996; Creevey, 2013; Sinha, 2010). An increase in the income would not have a sustainable impact on women unless the assets they possess increase to allow them a higher level and a more autonomous investment. Women should one day stop depending on the microcredit when enough capital has been accumulated, the credit being consequently used for ends of production and not of consumption.

\section{Schooling of Children}

The schooling of children is one of the most important variables to measure (Hashemi et al., 2013; Sinha, 2010). Indeed this variable reflects the greatest effect of the microcredit, that of the multiplier effect, when the impacts of a simple credit is extended over several generations. This is particularly interesting in the case of Egypt since the fight against illiteracy has had priority on the government agenda for several years now. Governmental campaigns and programs are set up to encourage families to send their children to school. If the offer of microcredit impacts the schooling of the children of the recipients, the governmental resources and efforts could be redirected towards other objectives. Moreover, the schooling of girls is especially important in the case of Egypt where boys always come first. Many efforts are devoted to the achievement of a greater equity in this field. 


\section{Health}

Health, or as we call it perception of health (since it is auto-evaluated by microcredit beneficiaries on a scale from 1 to 9) is chosen because health problems are important in Egypt and threaten people's productivity. The development of the third world countries is partly a result of health improvements. Microcredit would make it possible to women to have better treatments and more medical consultations (Amin et al., 2001). This is more important in the Egyptian context since the Egyptian social security and insurance systems are not very efficient.

\section{Harmony in the Family}

Finally, the perception of harmony in the family (auto-evaluated by participants) is chosen as the fifth variable of the study. By harmony in the family we mean the extent to which all members of the family are living peacefully without facing problems, quarrels or stressful events. Although it is not largely studied in the literature, we assume that this harmony is influenced positively by the microcredit if it could decrease the household difficulties by improving the economic status of the family. Microcredit could also have a negative impact on family harmony if it is perceived as disputing the primarily reproductive role of women.

\section{Methodology}

\section{Program Presentation}

It is interesting to first give a brief description of the program chosen for the completion of this research, since this is one of the most active and well established ones in Cairo. The program "El Tadamun" (solidarity) specializes in the offer of microcredit only, based on a minimalist approach of the offer. More than $90 \%$ of the program's beneficiaries work in the informal sector. The credit is granted according to the "group lending" mechanism. Each group comprises 5-15 participants, receiving the same amount of credit. When the research was undertaken, the number of the program participants was 7500 people and the program had a portfolio of 3.8 million Egyptian pounds (EGP).

The amount of the credit granted (at the first level of the program) was 500 EGP each 6 months; a partial refunding was carried out each 2 weeks, accompanied by an annual interest rate of $27 \%$.

\section{Sampling}

Since the study aimed at verifying the link between microcredit and the socioeconomic wellbeing of beneficiaries, the unit of analysis was the woman benefiting from a microcredit. In a world of abundant resources, a larger sample would have been selected. However, since the resources for the completion of this research, time and financial ones, were limited, the sample counted 100 women, clients of the above mentioned microcredit program. To study the effects of a policy or program and to link the observed changes to that program, most reviewed studies use what statisticians call a treatment group, in this case, women benefiting form the microcredit and a control 
group, women who do not benefit from the microcredit but who are otherwise similar to the members of the treatment group. Since finding women in the society with these similarities is difficult, our sample was divided equally in two groups:

- The experimental or treatment group: containing 50 women benefiting from the microcredit for at least 3 years to make sure that it had the time to have impact on their lives (if any).

- The comparison group: containing 50 women that have just joined the program in order to make sure that they have the requested similarities with the treatment group without being impacted by the microcredit yet.

Because the treatment and control group would differ (ideally) only by the fact that one group received the credit and the other did not, any observed differences could then, with some justifications, be largely attributed to the microcredit program. Few studies would compare the wellbeing of beneficiaries before receiving the microcredit and few years after receiving it, but we think that this approach is applicable only in a stationary environment since in reality, economic conditions are constantly changing and therefore, any observed changes in their wellbeing could be driven by changes in the economic environment rather than by microcredit. The recruitment of participants was made through the program officers using the program database of 7500 clients. The search and recruitment was operated by the program officers for confidentiality reasons. Also, five key microcredit experts were selected: two university professors and three microcredit officers, with whom interviews were performed.

\section{Data Collection}

Data was collected by the following means:

- Consultation of the program documents and registries to gather information about participation rules, mechanisms and functioning.

- One to one (personal) interviews with participants using open ended and closed ended questions. The questions were pre-tested to ensure their clarity and understandability by the participants who came from marginal classes and had different literacy levels.

- Meetings with key experts of the microcredit field, namely university professors who undertook academic research in that subject, and microcredit officers.

Research limitations include the fact that, some women were reluctant to answer some of the questions concerning their income and education levels. A good explanation of the research purpose made them more willing to cooperate.

Furthermore, if women thought that giving positive feedback about the program would increase their chances of getting more credit, the research would be biased. To avoid this, a detailed presentation of the researcher and the nature of the research helped making things clear and minimized such a risk. Finally, the abandon rate of the credit program would have represented a limitation of the research since it would have resulted in a difference between 
the profiles of the two groups and made them unfit for comparison. However, the fact that this rate was very low made this risk irrelevant.

\section{Analysis}

Most of the reviewed studies that aimed at testing the impact of microcredit on the socio-economic wellbeing of the beneficiaries used quantitative methods in the form of correlation and regression analyses where the indicators of wellbeing represented the dependant variables. Therefore, in our research, correlation was performed in order to test the existence of associations between the microcredit and our chosen dependent variables and indicate the possible effect sizes. Then, regressions were performed in order to test the causality and significance of such associations. It is worth noting that because our sample is relatively small, generalization should be avoided. However, given that very few if not at all studies were previously done to measure the impact of microcredit programs on beneficiaries; our hope was to shed some light on the following questions:

- What can be expected from the offer of microcredit on the welfare of recipients?

- Under what conditions would such an offer be more beneficial?

In order to answer these questions, on the one hand, beneficiaries were asked a wide range of questions like: the reason why they asked for the microcredit, in which sector of activity they are operating, how much money they make out of their activity, whether they have another source of income or not in order to separate it from the one they get from microcredit related activities. They were asked about the assets they possess and the way they use the money they earn, i.e., whether for investment/buying new assets or for consumption expenditures. They were required to specify how many of their children were getting education (segregated by gender) and why some did not. They were also asked about their health problems, and were asked to rate their health status, if they were getting any treatments and how they were financing such treatments in order to help understand whether microcredit was making their health any better or not. Also questions related to stability in family relations with husband and sons were addressed, ranking this "stability or absence of problems", and whether the microcredit they were getting was helping in making the relations inside their families more stable and harmonious or not. They were finally asked to add any comments they wanted to make about the abovementioned issues or any other microcredit related issue.

On the other hand, microcredit experts were asked to give their assessment of the efficiency of microcredit programs in Egypt in terms of outreach, planning and functioning and impact on both beneficiaries as well as on the economy.

The regression equations were formulated as follows:

- Income $=\mathrm{A} 1+\mathrm{B} 1$ micro $+\mathrm{C} 1$ age $+\mathrm{D} 1$ education $+\mathrm{F} 1$ marital status + G1 number of children $+\mathrm{D}$

- Assets = A2+B2micro + C2age+D2education + F2marital status + G2number of children $+\mathrm{D}$ 
- Schooling of girls $=\mathrm{A} 3+\mathrm{B} 3$ micro $+\mathrm{C} 3$ age $+\mathrm{D} 3$ education $+\mathrm{F} 3$ marital status + G3number of children $+\mathrm{D}$

- Schooling of boys $=$ A4+B4micro + C4age+D4education + F4marital status + G4number of children $+\mathrm{D}$

- Perception of health $=$ A5+B5micro + C5age+D5education + F5marital status + G5number of children+D

- Perception of the harmony in family $=$ A6+B6micro + C6age+D6education + F6marital status + G6number of children + D6

Where the independent variable was the use of microcredit, recent and since 3 years. The selected control variables were age, education, marital status and number of children.

\section{Analysis, Results and Hypothesis Validation}

As tables 1-3 show, that the microcredit is positively correlated to the income ( $\mathrm{r}=$ $0.738)$, positively correlated to the assets $(r=0.266)$, positively correlated to the schooling of girls $(r=0.381)$ and positively correlated to the schooling of boys $(r=0.406)$. However, correlation is not statistically significant between microcredit and the perception of health and the perception of the harmony in the family. These results are also confirmed by the regression coefficients. We find that in the "Income" equation the income of the beneficiary tends to increase on average by 153.505 Egyptian pounds per month when obtaining a microcredit. In fact, the average of women's income who did not receive a microcredit was 300 EGP. An increase of 153.5 represents more than a 50\% increase and shows that microcredit has a very important economic effect on the women receiving the credit. In the "Assets" equation, the fact of obtaining a credit is associated with an average increase of assets of 363.788 Egyptian pounds compared to those who do not benefit from a microcredit. In the "schooling of girls" equation, the schooling of the girls is associated with an average increase of $28 \%$ in the number of girls going to school in each household when obtaining a microcredit. In the same way, in the "schooling of boys" equation, their schooling is associated with an average increase of $30 \%$ in each household when obtaining a microcredit. Concerning the "perception of health" equation, we find that the microcredit coefficient is not significant, suggesting the absence of a link between the two variables. As for the "perception of the harmony in the family" equation, the microcredit coefficient is not statistically significant, suggesting the absence of a significant link between the harmony in the family and the fact of obtaining a microcredit.

Aside from whether or not did the microcredit had an impact on the beneficiaries wellbeing, it is important to know how much of a difference did the intervention possibly make in these women's lives. If we use the Cohen's benchmark for the economics field to interpret $r$ as an effect size estimate, we find that the effect of microcredit on income is a very large one while its effect on the schooling of girls, boys and possession of assets is medium. If we attempt to characterize the strength of this measure of effect size using the proportion of variance explained by squaring the correlation coefficients in order to try to estimate the relationship in the context of the total variance we find for example that 
microcredit accounts for almost 55\% of the variance on income. A deeper look at the economic and social significance of these results is presented as follows.

Table 1: Correlation Results

\begin{tabular}{|c|c|c|c|c|c|c|c|c|c|c|c|}
\hline & 照 & 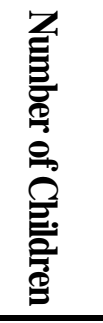 & 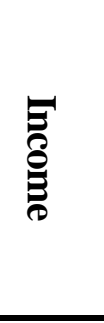 & $\begin{array}{l}\text { जै: } \\
\text { है } \\
\text { है }\end{array}$ & 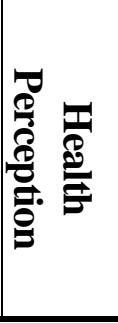 & 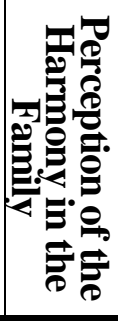 & & 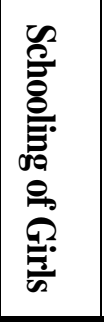 & 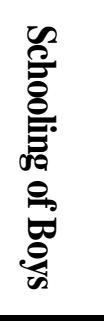 & 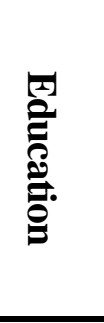 & 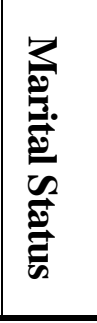 \\
\hline Age & 1 & .471 & .013 & -.010 & -.394 & -.147 & .000 & -.020 & -.043 & -.307 & .366 \\
\hline Number of Children & .471 & 1 & .231 & .250 & -.296 & .029 & .171 & -.059 & .018 & -.239 & -.067 \\
\hline Income & .013 & .231 & 1 & .455 & -.057 & .226 & .738 & .209 & .372 & .050 & -.089 \\
\hline Assets & -.010 & .250 & .455 & 1 & .067 & .213 & .266 & .213 & .227 & .112 & -.191 \\
\hline Health Perception & -.394 & -.296 & -.057 & .067 & 1 & .365 & -.032 & .017 & -.097 & .209 & -.187 \\
\hline $\begin{array}{l}\text { Perception of the } \\
\text { Harmony in the Family }\end{array}$ & -.147 & .029 & .226 & .213 & .365 & 1 & .122 & .012 & .093 & .148 & -.577 \\
\hline Credit & .000 & .171 & .738 & .266 & -.032 & .122 & 1 & .381 & .406 & .022 & .000 \\
\hline Schooling of Girls & -.020 & -.059 & .209 & .213 & .017 & .012 & .381 & 1 & .163 & .154 & .098 \\
\hline Schooling of Boys & -.043 & .018 & .372 & .227 & -.097 & .093 & .406 & .163 & 1 & .065 & -.135 \\
\hline Education & -.307 & -.239 & .050 & & .209 & .148 & .022 & .154 & .065 & 1 & -.153 \\
\hline Marital Status & -.366 & .067 & .089 & & .187 & .577 & .000 & -.098 & .153 & .153 & 1 \\
\hline Sample & 100 & 100 & 100 & & 100 & 100 & 100 & 84 & 90 & 100 & 100 \\
\hline
\end{tabular}

Table 2: Regression Results

\begin{tabular}{l|c|c|c|c|c|c}
\hline \hline & Income & Assets & $\begin{array}{c}\text { Health } \\
\text { Percepti } \\
\text { on }\end{array}$ & $\begin{array}{c}\text { Perception of the } \\
\text { Harmony in the Family }\end{array}$ & $\begin{array}{c}\text { Schooling } \\
\text { for Girls }\end{array}$ & $\begin{array}{c}\text { Schooling } \\
\text { for Boys }\end{array}$ \\
\hline \hline Age Coefficient & 0.036 & -2.901 & -0.032 & 0.020 & 0.003 & 0.001 \\
& $(0.024)$ & $(-.296)$ & $(-2.173)$ & $(1.371)$ & $(0.600)$ & $(0.214)$ \\
\hline Micro Credit & 253.504 & 363.788 & -0.016 & 0.377 & 0.284 & 0.306 \\
Coefficient & $(10.307)$ & $(2.279)$ & $(-0.069)$ & $(1.608)$ & $(3.679)$ & $(4.163)$ \\
\hline Education & 19.707 & 246.227 & 0.211 & 0.225 & 0.106 & 0.055 \\
Coefficient & $(0.486)$ & $(1.347)$ & $(0.776)$ & $(0.836)$ & $(1.190)$ & $(0.644)$ \\
\hline Marital Status & 30.812 & 271.136 & 0.262 & 2.043 & -0.084 & 0.117 \\
Coefficient & $(0.969)$ & $(1.313)$ & $(0.852)$ & $(6.732)$ & $(-0.855)$ & $(1.199)$ \\
\hline Number of Children & 9.585 & 99.011 & -0.094 & -0.058 & -0.022 & -0.009 \\
Coefficient & $(1.374)$ & $(2.187)$ & $(-1.396)$ & $(-0.874)$ & $(-0.968)$ & $(-0.373)$ \\
\hline Constant & 153.078 & 1049.207 & 7.731 & 5.503 & 0.333 & 0.365 \\
& $(2.680)$ & $(2.830)$ & $(13.991)$ & $(10.096)$ & $(1.727)$ & $(2.174)$ \\
\hline Adjusted R ${ }^{2}$ & 0.542 & 0.119 & 0.140 & 0.330 & 0.130 & 0.141 \\
\hline Standard Error & 120.27249 & 780.67138 & 10.16356 & 1.14764 & 0.3416 & 0.34084 \\
\hline F score & 24.387 & 3.676 & 4.221 & 10.773 & 3.490 & 3.922 \\
\hline F probability & 0.000 & 0.004 & 0.002 & 0.000 & 0.007 & 0.003 \\
\hline \hline
\end{tabular}


The Effect of Relationship Marketing...

Table 3: Hypothesis Validation

\begin{tabular}{l|c|c|c}
\hline \hline \multicolumn{1}{c|}{ Variable } & $\begin{array}{c}\text { Correlation with } \\
\text { Microcredit }\end{array}$ & $\begin{array}{c}\text { Regression Coefficient of } \\
\text { Microcredit in the Equation }\end{array}$ & $\begin{array}{c}\text { Validation of the } \\
\text { Hypothesis }\end{array}$ \\
\hline \hline Income & .738 & $253.504 \mathrm{t}$ value $(10.307)$ & Confirmed \\
\hline Assets & .266 & $363.788 \mathrm{t}$ value $(2.279)$ & Confirmed \\
\hline Schooling of Girls & .381 & $0.284 \mathrm{t}$ value $(3.679)$ & Confirmed \\
\hline Schooling of Boys & .406 & $0.306 \mathrm{t}$ value $(4.163)$ & Confirmed \\
\hline Health Perception & -.032 & $-.016 \mathrm{t}$ value(-.069) & Refuted \\
\hline $\begin{array}{l}\text { Perception of the } \\
\text { Harmony in the Family }\end{array}$ & .122 & $.377 \mathrm{t}$ value(1.608) & Refuted \\
\hline \hline
\end{tabular}

The results are in fact extremely interesting and conclusive, which can be explained in the light of the socio-economic context in which the microcredit is offered as well as that in which the women benefiting from the microcredit live and use it. We will attempt to interpret and show the implications of the results. Furthermore, the outcome of the experts' interviews are presented, the whole leading to policy recommendations in Section 7.

\section{Women's Wellbeing}

1- Income. Positive association with microcredit: hypothesis confirmed and in line with the literature. This effect is extremely important and leads to economic empowerment of the credit takers vis a vis their suppliers.

In fact, before obtaining the loan, women were forced to accept their suppliers' terms, among which sub standard products, since they would delay payment till after selling. One woman revealed during the interviews:

"My supplier was very mean, as I did not have enough liquidity; he gave me only the goods remaining at the end of the day. These were very bad and sometimes even damaged. I could not select the good vegetables I want or even try not to take the rotten ones because then he would give me nothing. It was a 'take it or leave it' deal. Thus, I always had a part of the vegetables unsold while I was to pay him for the totality of what he provided me with. I always had losses to undergo. Today I am not facing anymore this blackmail; I have the faculty to choose what I want!" After obtaining the microcredit, they would be able to pay suppliers on the spot and hence refuse harsh conditions. The Vicious circle is thus broken with their ability to take their own decisions that would positively enhance their profit and business. The women could also, before, borrow money from their family or their friends and neighbors to finance their purchases of goods. They underwent in this case the humiliation and the feeling of deterioration of their social status. In fact one woman told us during the interviews: "My parents-in-law called me worthless and obliged me to make them housework because they lent me the money I needed for the purchase of the goods. Of course I refunded them, but this kind of humiliation was like the price to be paid, the interest rate of the loan!" Therefore, self-esteem and confidence are enhanced when women get the microcredit and when their income increases because they feel economically independent. Furthermore, the increase in income allows them to answer basic needs of 
consumption and survival expenditures that they could not face before, increasing their wellbeing and empowering them.

Another important point to note when talking about income is that one of the questions asked to women participating in this study was related to the nature of the activity or the project they start when they obtain the microcredit. The answers were divided into five categories of activities and the results showed that almost $50 \%$ of observed women work in the retail selling of household articles like bed sheets in a limited geographic area, which limits the income they earn because they had to go through very severe price competition. Furthermore, questions relative to the other sources of women's income were included in the questionnaire. We thus used these answers to try to understand what motivates women to require the microcredit. $80 \%$ of the women are financially unstable: they have no other source of income and suffer as a result of the husband volatile income of temporary jobs. This shows that a shift of economic roles is occurring, a role that one was accomplishing (the husband) is now assumed by another (the wife).

\section{Assets.}

Positive association with microcredit: hypothesis confirmed and in line with the literature. This result reflects a long-term amelioration of the beneficiaries' wellbeing. This amelioration is sustainable because the increase in their income is reinserted and invested in the assets they possess. However, one should notice that sometimes the increase occurred in households and personal assets (like TV and others) and not production ones. Furthermore, some used all their income and profits for consumption purposes. Some did not know how to invest their extra income in the project because they lacked the appropriate skills.

Indeed, a woman affirmed during the interview:

"I decided to take the microcredit because children's needs are unlimited; so much money is needed for their daily survival and wants, namely schooling private lessons and girls marriage preparations. I have always borrowed money from friends and family but now the profit I make from my small project is sufficient".

Another one declared:

"No substantive difference in the size of my project happened after I obtained the microcredit. It simply helped me to have more liquidity to better spend on my children and my house".

Children's schooling.

Positive association with microcredit: hypothesis confirmed and in line with the literature.

This result is one of the most interesting of our study and is the reason why most international organizations target women when offering microcredit. The enhancement of the children's schooling represents a multiplier effect of giving credit to women. Thus investing in one generation goes further to the next generations and the investment is bigger. Women declare that their children education is the most important investment they 
can make and their priority since they did not have such a chance when they were young. They therefore want to give this chance to their children. They also believe that their children can have a better future with better education. Nadia, who has just joined the program, has five boys and a girl. She said during the interview: "My children were not getting any schooling because my very modest income does not allow it. It made me feel very bad".

Another simply answered when we asked her to tell us the reason for which she asked for the microcredit: "to provide education for my children!".

They also mentioned that a higher level of education of their children is reflected by a higher amount of private lessons since in Egypt private lessons became indispensable for good achievement at school.

A major interesting result of the study was that there is no significant difference between the coefficients of schooling for girls and boys, which reflects a deep transformation in the society. Traditionally, Egyptians favored the schooling of boys since girls would get married and look after a husband and family, whereas the boy would be the only bread earner of his future family. Nowadays they consider that the schooling of both girls and boys are equally important since education will help girls get a "better" husband, hence a more decent life, whereas boys need less "theoretical" education and more "practical" experience to get a better job. This also reflects the cultural and social dimension of the decisions they make.

Finally, and as mentioned before, this result is particularly interesting in the case of Egypt since the fight against illiteracy has had priority on the government agenda for several years now. Governmental campaigns and programs are set up to encourage families to send their children to school. Thus, the governmental resources and efforts could be redirected towards other objectives.

\section{Health Perception.}

No significant association with microcredit: hypothesis refuted and goes against the direction of the literature. This result shows that women place their health in a low position on their priority list: when applying the rational choice principle, the schooling of their children, feeding the family members and other types of surviving expenditures, as well as some luxury allowances (such as buying better clothes or entertainment) come first. Most have been raised to the belief that they are inferior to others and should always sacrifice themselves and serve other family members (like father and brothers before marriage and husband and children after marriage).

They consider that the expenditures related to their personal wellbeing have less priority than the others that are impossible to circumvent. One could even believe, that the fact of choosing the improvement of the fate of their family and children, and of answering needs impossible to avoid (payment of debts and various payments for daily survival) would increase their satisfaction and personal wellbeing indirectly much more than if they carried out direct expenditure for their own person. 
Finally, most women still depend on the government medical health insurance which is free but is generally not very efficient due to low quality of services offered.

\section{Perception of the Harmony in the Family.}

Positive non-significant association with microcredit: hypothesis refuted.

This hypothesis needs a bigger sample to see if it gets confirmed or not, since small effects need larger samples to be confirmed.

As mentioned before, the choice of this variable in the study was due to the Egyptian special context which considers that women's work outside the house is taboo and views their main role as caring for the family. We therefore wanted to test how a change in this role would affect the harmony of the household. This effect could either be reflected by increasing conflicts because of the husband or children disapproval of the woman new role, or by enhancing the family stability as a result of the household income increase. Responses were much diversified regarding this issue among women. Some mentioned that microcredit threatened their family stability because the husband disapproved the activity they were undertaking, while others said that tension in the family decreased because of the improved economic conditions they experience. A participant announced:

"I wanted to undertake an income generating activity to avoid the problems and family quarrels caused by the lack of money", whereas many said that they could not report any significant change in that area.

Most of the microcredit programs in Cairo are "survival" programs since they only help women survive by getting some extra income (through the activity they undertake) for their daily expenses. No substantive investment is made in most of the programs and thus no real sustainable effect. They are also minimalist programs not pluralist ones since they only offer credit without any other accompanying services (like training or marketing). Coupled with the women's lack of skills, this helps increase the first effect (survival not promotional). According to Dr. Alia El Mahdi, Professor of Economics at Cairo University and one of the main scholars working on SMEs in Egypt, this is the reason why some programs do not offer microcredit to "start-ups" and require that the project applying for the credit must be running for at least 6 months.

In fact, Dr. Manal Metwali, Professor of Economics at Cairo University and expert in the field of microfinance, mentioned that:"it is necessary to provide other non-financial services to women to help them better manage the microcredit. This can significantly improve the product they offer and increase the chances of success of the project. If the program is limited to the offer of the microcredit, and if the only concern of the beneficiary is to have the credit and reimburse it, one will face a simple vicious circle of loan and refunding. The objective should rather be the success of the projects via the offer of services. Even if the program does not directly offer the services, it could make available the information about it and provide a network of useful services.

Furthermore, there is a big competition between different programs offering microcredit in the same geographic zone encouraging women to switch from one program to 
another for no specific reason and consequently limits the positive impact of such programs. Some regions have a surplus of offer of credit and others have a lack of such an offer. There is therefore a need for a better planning of the existing programs.

\section{Conclusion and Policy Recommendations}

Microcredit has become a very important tool used internationally to combat poverty and enhance the social and economic wellbeing of its recipients (Nader, 2008). Women are specifically targeted because they are very vulnerable before economic changes, they lack the necessary resources to adapt to such changes and because they tend to invest largely in their families and benefit their children of the microcredit outcomes. The aim of this research was twofold: first, it wanted to confirm or refute a positive link between microcredit and the socio-economic wellbeing of women in Cairo and second, to explore the context in which microcredit programs function in Egypt and the way their performance can be improved. The purpose was to shed some light on the following questions:

- What can be expected from the offer of microcredit on the welfare of recipients?

- Under what conditions would such an offer be more beneficial?

The results revealed very interesting and important policy implications. It was very important to notice that the increase in women's income and assets played a very important role in enhancing women's economic independence and sense of self-confidence. It helped breaking the cycle of poverty they live in and allowed them to have more control over their lives and economic decisions. But on the other hand, both the quantitative analysis of the microcredit recipients' answers as well as the interviews with the experts showed that this increase was small and that the strategy followed by some programs offering the microcredit resembles that of the subsidies system, targeting survival only, without helping in substantially transforming these women's lives. This was mainly caused by the small amount of credit offered and that these women lacked the skills needed to engage in highly profit making activities. We believe that a very important policy recommendation is the necessity of reviewing the existing programs and the way microcredit is offered in Egypt. Programs should shift from the simplistic ones to pluralistic ones that offer services besides the microcredit (i.e., marketing, match-making, training). It is necessary to redirect microfinance towards developmental activities that will contribute to the improvement, in the long run, of the wellbeing of the recipients. The development would be possible when the credit allows real and substantial investments in the production/investment capital and assets, not only personal assets.

We believe that the most important result revealed by our study is related to the link between receiving a microcredit and the increase in schooling of the recipients' children, both girls and boys. Furthermore, it showed that no significant difference existed between the increase in the enhancement of schooling of boys and girls. This result must be encouraged and invested in. Lot of public policies and programs previously targeted raising the awareness related to the importance of such an issue. If microcredit programs build upon this effect, and further encourage it, public expenditures that were allocated to target this issue will be saved. 
Another observation raised by the microcredit experts as well as some participants was the lack of planning when it comes to the geographical distribution of the programs nationwide as well as the lack of a specific vision for the offer of the microcredit. There is a need to revisit the different existing programs, to rethink the rationale of the offer of microcredit and the macroeconomic goal that needs to be achieved through it and reorganize the offer accordingly. This will optimise the use of the resources dedicated to these programs. There is a need for more studies about better practices in the microcredit field in order to achieve maximum benefits for clients, namely in terms of minimalist versus pluralist, survival/protectionist versus promotional, institutionist versus wellfarist strategies and approaches. More impact assessments of the existing programs must be performed to help in identifying strengths and weaknesses and the appropriate incentives that can be offered to support the offer of microcredit and its impact on the beneficiaries as well as on the whole economy (El Hadidi, 2018). 


\section{References}

- Amin, R., M. St. Pierre; A. Ahmed and R. Haq. (2001). "Integration of an Essential Services Packages (ESP) in Child and Reproductive Health and Family Planning with a Micro Credit Program for Poor Women: Experience from a Pilot Project in Rural Bangladesh", World Development, 29, (9).

- Buckley, G. (2014). "Microfinance in Africa, is it Either the Problem or the Solution?", World Development, 25, (7).

- Cerrutti, M. (2013). "Economic Reform, Structural Adjustment, and Female Labor Force Participation in Buenos Aires, Argentina", World Development, 28, (5), 879-891.

- Chaves, R. and C. Gonzalez-Vega. (2010). "The Design of Successful Rural Financial Intermediaries: Evidence from Indonesia", World Development, 24, (1).

- Creevey, L. (2013). Changing Women's Lives and Work: an Analysis of the Impacts of Eight Microenterprise Projects. IT Publications, Unifem.

- Doumato, E. and M. Posusney. (2013). Women and Globalization in the Arab Middle East, Gender, Economy and Society. Lynne Rinner Publishers.

- El Solh, C. (1999). Feasibility and operationalization of microcredit finance facilities targeting poor women in urban and rural areas in selected Arab countries, New York: United Nations (Economic and Social Commission for Western Asia).

- El-Hadidi, H. (Forthcoming). The Impact of Microfinance on Female Empowerment in Egypt. The Arab Journal for Amdministration, Cairo: Arab Administrative Development Organization (ARADO).

- Elson, D. (2014). Male Bias in the Development Process. St. Martin Press, New York.

- Hashemi, S. M. and S. R. Schuler. (2013). "Rural Credit Programs and Women's Empowerment in Bangladesh", World Development, 24, No. 4, 635-653.

- Johnson, S. and B. Rogaly. (2010). Microfinance and Poverty Reduction. Oxfam, UK and Ireland.

- Kabber, N. (2016). "Resources, Agency, Achievements: Reflections on the Measurement of Women's Empowerment", Development and Change, 30, 435-464.

- Khander, S. (1998). "Microcredit Programme Evaluation: A Critical Review", IDS Bulletin, 29, University of Sussex, UK.

- Nader, F. Y. (2008). Microcredit and the Socio-economic Wellbeing of Women and Their Families in Cairo. The Journal of Socio-Economics, 37, 644-656.

- Nelson, C.; B. Mknelly; K. Stack and L. Yanovitch. (1996). Village Banking, the State of the Practice. UNIFEM.

- Ritu, D. (2015). "Gender Implications of the New Economic Policy: A Conceptual Overview", Women's Studies International Forum, 22, (4).

- Sinha, S. (2010). "Micro-credit: Impact, Targeting and Sustainability", IDS Bulletin, 29, (4). 